\title{
Androgen Receptor Gene CAG Repeat Polymorphism Regulates the Metabolic Effects of Testosterone Replacement Therapy in Male Postsurgical Hypogonadotropic Hypogonadism
}

\author{
Giacomo Tirabassi, ${ }^{1}$ Nicola delli Muti, ${ }^{1}$ Giovanni Corona, ${ }^{2,3}$ \\ Mario Maggi, ${ }^{3}$ and Giancarlo Balercia ${ }^{1}$ \\ ${ }^{1}$ Andrology Unit, Division of Endocrinology, Department of Clinical and Molecular Sciences, Umberto I Hospital, \\ Polytechnic University of Marche, 60126 Ancona, Italy \\ ${ }^{2}$ Endocrinology Unit, Azienda Usl di Bologna, Maggiore-Bellaria Hospital, Bologna, Italy \\ ${ }^{3}$ Andrology Unit, Department of Clinical Physiopathology, University of Florence, Florence, Italy \\ Correspondence should be addressed to Giancarlo Balercia; g.balercia@ospedaliriuniti.marche.it
}

Received 26 September 2013; Accepted 4 November 2013

Academic Editor: Maria L. Dufau

Copyright (C) 2013 Giacomo Tirabassi et al. This is an open access article distributed under the Creative Commons Attribution License, which permits unrestricted use, distribution, and reproduction in any medium, provided the original work is properly cited.

\begin{abstract}
Aim. To evaluate the independent role of androgen receptor (AR) gene CAG repeat polymorphism on metabolic effects of testosterone replacement therapy (TRT) in male postsurgical hypogonadotropic hypogonadism, a condition frequently associated with hypopituitarism and in which the TRT-related metabolic effects are combined with those deriving from concomitant administration of metabolically active pituitary-function replacement therapies. Methods. 15 men affected by postsurgical hypogonadotropic hypogonadism were evaluated before and after TRT. Cardiovascular risk factors (CVRFs), pituitary-dependent hormones, and AR gene CAG repeat polymorphism were considered. Results. Testosterone, insulin-like growth factor 1 (IGF-1), and estradiol were the only hormones, which varied significantly between the two phases. All CVRFs significantly improved after TRT. The number of CAG triplets was positively and significantly correlated with all the variations $(\Delta-$ ) of CVRFs (except for a significant negative correlation with $\Delta$-high-density lipoprotein); the opposite occurred between the latter and $\Delta$-testosterone. No correlation between $\Delta$-IGF-1 or estradiol and $\Delta$-CVRFs was found. At multiple linear regression, after correction for $\Delta$-testosterone, nearly all the associations between the number of CAG triplets and $\Delta$-CVRFs were confirmed. Conclusions. In male postsurgical hypogonadotropic hypogonadism, shorter AR gene CAG tract length seems to yield greater metabolic improvement after TRT, independently of the effects of concomitant pituitary-function replacement therapies.
\end{abstract}

\section{Introduction}

The androgen receptor (AR) gene is located on X chromosome at q11-q12 and is composed of eight exons [1]. Exon 1 of the AR gene contains a polymorphic sequence of CAG repeat, which varies in number from 10 to 35 [2] and which encodes polyglutamine stretches of AR transactivation domain [3]. Evidence suggests that CAG number is inversely correlated to the transcriptional activity of AR [2]. In fact, subjects affected by Kennedy Syndrome present a number of CAG repeats greater than 40 together with decreased virilization, testicular atrophy, reduced sperm production, and infertility [4]. Similarly, other studies have shown that shorter CAG repeats are associated with prostate cancer [5], benign prostatic hypertrophy [6], prostate increase during androgen treatment [7], improved seminal parameters [8, 9], and improved mineral bone density [10].

However, great uncertainty exists in the literature regarding the association between AR gene CAG repeat polymorphism and metabolic profile. In fact, while some authors found a connection of the low number of CAG repeats with low high-density lipoprotein (HDL) cholesterol levels $[8,11]$ 
and with increased severity of coronary heart disease [12], others reported a relationship between the high number of CAG repeats and worse cardiovascular risk factors (CVRFs) [13]. These results are derived from transversal studies which did not examine hypogonadal patients. In particular, very little is known about the role AR gene CAG repeat polymorphism plays in influencing long-term metabolic effects of testosterone replacement therapy (TRT).

Given this premise, we decided to evaluate the independent effect of AR gene CAG repeat polymorphism on TRT-related metabolic changes, focusing on male postsurgical hypogonadotropic hypogonadism, a condition which is nearly always associated with hypopituitarism and requires the concomitant administration of metabolically active hormone replacement therapies, such as recombinant growth hormone (GH), levothyroxine, and cortisone [14-18].

\section{Materials and Methods}

2.1. Subjects. 15 males treated in our clinic were retrospectively evaluated. Inclusion criteria were, (a) hypogonadotropic hypogonadism $[19,20]$ secondary to surgical removal of pituitary adenoma, (b) absence of hypophyseal adenoma hypersecretion before surgery, (c) absence of hypophyseal hormone deficit before surgery, (d) absence of hypogonadism before surgery, (e) presence of clinical follow-up data for the whole length of the study, and (f) absence of previous diseases able to condition metabolic parameters considered in this study (e.g., diabetes mellitus, dyslipidaemia, arterial hypertension, etc.).

2.2. Study Protocol. The studied subjects underwent clinical and biochemical evaluation at the beginning of TRT (time 0 ) and before the eighth undecanoate testosterone injection (74-84 weeks after the first testosterone injection) (recovery phase). $1000 \mathrm{mg}$ of undecanoate testosterone was administered intramuscularly after 6 weeks before the first injection (loading dose), followed by similar injections every 10-14 weeks, depending on blood testosterone values and clinical symptoms [21]. All subjects presented both somatotropic and gonadotropic function deficits $[19,20,22]$; among them, four had also thyreotropic [23], two also corticotropic [24], and three both thyreotropic and corticotropic function deficits. All patients were treated with appropriate doses of glucocorticoid (cortisone acetate, $37.5-50 \mathrm{mg}$ daily), somatotropic (recombinant human GH, 0.3-0.6 mg daily), and thyroid (levothyroxine, 75-100 $\mu$ daily) replacement therapy, depending on the specific hormone deficit. Glucocorticoid and thyroid replacement therapy began in the hours/days immediately after surgery, depending on the presence and degree of the specific deficit. Somatotropic replacement therapy and TRT were started between 6 and 12 months after surgery; no subject was given GH replacement therapy before TRT. Duration of hypogonadism was calculated as the time between surgery and beginning of TRT (time 0 ).

This is a retrospective study and the data examined were part of the diagnostic work-up, except for genetic data which were collected as part of a research protocol. The study was performed according to the Declaration of Helsinki and approved by the institutional ethics committee. An informed consent was obtained from each individual.

2.3. Clinical Evaluation. Among the measured clinical parameters, weight, waist circumference, systolic (SBP), and diastolic blood pressure (DBP) were considered in the analysis. Weight, waist circumference, SBP, and DBP were collected according to standard methods previously described $[25,26]$.

2.4. Biochemical and Hormone Evaluation. Blood samples were taken in the morning. The following biochemical and hormone parameters were considered: glycaemia, glycated hemoglobin (HbAlc), total cholesterol, HDL cholesterol, triglycerides, basal insulinemia, follicle-stimulating hormone (FSH), luteinizing hormone (LH), total testosterone, estradiol, free T3 (FT3), free T4 (FT4), cortisol, insulin-like growth factor-1 (IGF-1), and prolactin.

Plasma glucose was measured by photometric determination using the hexokinase method. HbAlc was measured in whole blood using ion-exchange high performance liquid chromatography with the Bio-Rad Variant Haemoglobin Testing System (Bio-Rad Laboratories, Hercules, CA, USA). Total cholesterol, HDL cholesterol, and triglycerides were assayed enzymatically with a final Trinder reaction (ADVIA 2400 SIEMENS, Bayer Diagnostics, Tarrytown, NY, USA). All hormone assays were carried out using immunoassay commercial kits. As far as total testosterone is concerned, its assay was performed using ADVIA centaur XP immunoassay, SIEMENS Medical Solution Diagnostics (minimum detectable concentration: $0.1 \mathrm{ng} / \mathrm{mL}$; intra- and interassay coefficients of variation were, respectively, $6.2 \%$ and $4.4 \%$ at a testosterone concentration of $0.95 \mathrm{ng} / \mathrm{mL}$ and $4.7 \%$ and $4.7 \%$ at $3.65 \mathrm{ng} / \mathrm{mL}$ ). The normal reference ranges for the biochemical parameters studied were the following: plasma glucose, $70-99 \mathrm{mg} / \mathrm{dL}$; HbAlc, $<6.0 \%$; total cholesterol, $<200 \mathrm{mg} / \mathrm{dL}$; HDL cholesterol, $>40 \mathrm{mg} / \mathrm{dL}$ for males; triglycerides, $<150 \mathrm{mg} / \mathrm{dL}$; basal insulinemia, $4-23 \mu \mathrm{U} / \mathrm{mL}$; FSH, 1.7-6.9 IU/L; LH, 1.6-10.0 IU/L; total testosterone, 3$8.5 \mathrm{ng} / \mathrm{mL}$; estradiol, $11-47 \mathrm{pg} / \mathrm{mL}$; FT3, 2.3-4.2 pg/mL; FT4, $0.8-1.8 \mathrm{ng} / \mathrm{dL}$; serum cortisol ( $8.00 \mathrm{am}), 7-27.5 \mathrm{mcg} / \mathrm{dL}$; IGF$1,66-251 \mathrm{ng} / \mathrm{mL}$ for males between 40 and 50 years; $57-$ $221 \mathrm{ng} / \mathrm{mL}$ for males between 50 and 60 years; $46-211 \mathrm{ng} / \mathrm{mL}$ for males between 60 and 70 years; prolactin, $2-15 \mathrm{ng} / \mathrm{mL}$.

Insulin sensitivity was assessed by the homeostasis model assessment of insulin resistance (HOMA-IR) [25], which is calculated as follows: [fasting plasma glucose $(\mathrm{mmol} / \mathrm{L}) \times$ fasting insulin $(\mathrm{mU} / \mathrm{L})] / 22.5$. Low density lipoprotein (LDL) cholesterol was calculated according to the Friedewald et al. [27] formula: LDL cholesterol $=$ total cholesterol $-\mathrm{HDL}$ cholesterol - triglycerides/5.0 (mg/dL).

2.5. Polymerase Chain Reaction (PCR) Amplification and Sequencing. AR gene CAG repeats genotyping was performed as previously described [28]. Briefly, genomic DNA was isolated from peripheral leukocytes. PCR assay was performed with $150 \mathrm{ng}$ DNA; primers were used at final concentration of $10 \mathrm{mM}$. The hot-start technique was used to 
TABLE 1: General and hormonal characteristics of studied subjects.

\begin{tabular}{|c|c|c|c|c|}
\hline \multicolumn{5}{|c|}{ General characteristics } \\
\hline Age (years) & \multicolumn{4}{|c|}{$55.66 \pm 8.64$} \\
\hline Duration of hypogonadism (months) & \multicolumn{4}{|c|}{$8.46 \pm 1.88$} \\
\hline Number of AR gene CAG triplets & \multicolumn{4}{|c|}{$18.13 \pm 3.41$} \\
\hline \multicolumn{5}{|c|}{ Hormonal characteristics } \\
\hline & Time 0 & Recovery phase & $\Delta$ & $P^{+++}$ \\
\hline FSH (IU/L) & $0.90(0.70-1.10)$ & $0.70(0.50-0.90)$ & $-0.40(-0.60-0.20)$ & NS \\
\hline LH (IU/L) & $0.92 \pm 0.40$ & $0.78 \pm 0.26$ & $-0.14 \pm 0.37$ & NS \\
\hline Total testosterone $(\mathrm{ng} / \mathrm{mL})$ & $1.53 \pm 0.52$ & $3.96 \pm 0.36$ & $2.42 \pm 0.70$ & $<0.001$ \\
\hline Estradiol $(\mathrm{pg} / \mathrm{mL})$ & $7.66 \pm 1.95$ & $32.80 \pm 10.31$ & $25.13 \pm 11.13$ & $<0.001$ \\
\hline FT3 $(\mathrm{pg} / \mathrm{mL})$ & $3.24 \pm 0.50$ & $3.11 \pm 0.46$ & $-0.12 \pm 0.74$ & NS \\
\hline FT4 (ng/dL) & $1.24 \pm 0.28$ & $1.33 \pm 0.18$ & $0.08 \pm 0.40$ & NS \\
\hline Cortisol (mcg/dL) & $14.70(12-16.80)$ & $13.50(11.40-17.20)$ & $0.80(-5-1.5)$ & NS \\
\hline IGF-1 (ng/mL) & $34.93 \pm 7.59$ & $153.13 \pm 41.05$ & $118.20 \pm 43.73$ & $<0.001$ \\
\hline Prolactin $(\mathrm{ng} / \mathrm{mL})$ & $6.82 \pm 2.97$ & $7.35 \pm 3.17$ & $0.52 \pm 4.86$ & NS \\
\hline
\end{tabular}

Values are expressed as median (interquartile range) or mean \pm standard deviation.

${ }^{+++}$Statistical comparison between time 0 and recovery phase.

AR: androgen receptor; $\Delta$ : variation; FSH: follicle-stimulating hormone; LH: luteinizing hormone; FT3: free T3; FT4: free T4; IGF-1: insulin-like growth factor-1; NS: not significant.

prevent nonspecific amplification. PCR products were purified using QIAquick PCR Purification Kit (Qiagen, Hilder, Germany) and approximately $30 \mathrm{ng}$ of the purified products was submitted to a sequencing reaction with the BigDye Terminator v3.1 Cycle Sequencing Kit (ABI Prism; Applied Biosystem). The samples were sequenced on a CEQ $2000 \mathrm{XL}$ sequencer (Beckman Coulter, Fullerton, CA, USA).

2.6. Statistical Analysis. Shapiro-Wilk's test was applied to verify the normal distribution of the continuous variables. Data are expressed as median (interquartile range) when not-normally distributed and as mean \pm standard deviation when normally distributed. CVRFs and hormone variations between the two phases $(\Delta-)$ were calculated as the value present at the recovery phase minus the value present at time 0 ; statistical comparison between the two phases was made using Student's $t$-test for paired data or the Wilcoxon test depending, respectively, on normal or nonnormal data distribution. In order to study the effect of AR gene CAG polymorphism on metabolic parameters, independently from that of the administered hormones, a two-step approach was adopted. First, Pearson correlations of the various significant hormonal variations and number of CAG triplets with $\Delta$ CVRFs were carried out. Then, multiple linear regression analysis was performed including as dependent variables the $\Delta$-CVRFs, one at a time, and as independent ones the variables which, in the Pearson correlation, were significantly correlated with $\Delta$-CVRFs. Significance was set at $P<0.05$. Statistical analyses were performed using SPSS 16 package (SPSS Inc., Chicago, IL, USA).

\section{Results}

Table 1 presents general and hormone parameters of the studied subjects. Testosterone, IGF-1, and estradiol varied significantly between the two phases, while the other hormones did not change significantly (Table 1). Conversely, all metabolic variables improved significantly after TRT (Table 2). Table 3 shows the Pearson correlations of statistically significant hormonal variations $\left(\Delta^{-}\right)$between the two phases, that is, testosterone, IGF-1, and estradiol, and of the number of CAG triplets with the $\triangle$-CVRFs. The number of CAG triplets correlated positively and significantly with all the $\Delta$-CVRFs (except for the significant and negative correlation with $\Delta$-HDL cholesterol) (Table 3 ). On the contrary, $\Delta$-testosterone correlated negatively and significantly with all $\Delta$-CVRFs (except for the significant and positive correlation with $\Delta$-HDL cholesterol), while $\Delta$-IGF-1 and estradiol did not correlate significantly with any of the $\Delta$-CVRFs (Table 3 ). Multiple linear regression analysis was carried out including as dependent variables the $\Delta-C V R F$ s and as covariates both the number of CAG triplets and $\Delta$-testosterone. After adjusting for $\Delta$-testosterone, CAG repeat length was still positively and significantly associated with $\Delta$-weight, $\Delta$-glycemia, $\Delta$ HbAlc, $\Delta$-triglycerides, $\Delta$-HOMA-IR, $\Delta$-SBP, $\Delta$-DBP, and negatively with $\Delta$-HDL cholesterol (Table 4); positive and almost significant $(P=0.05)$ association was also evident with $\Delta$-LDL cholesterol (Table 4$)$.

\section{Discussion}

In this work we evaluated the impact of AR gene CAG polymorphism length on metabolic effects of TRT, focusing on male postsurgical hypogonadotropic hypogonadism, a condition in which this aspect has not yet been studied. As already anticipated, postsurgical hypogonadotropic hypogonadism is a particular type of hypogonadism in which TRT-related metabolic changes combine with those deriving from the frequent concomitant administration of pituitaryfunction replacement hormones [14-16, 29, 30]. In fact, 
TABLE 2: Metabolic profile of subjects studied in the two phases.

\begin{tabular}{|c|c|c|c|c|}
\hline & Time 0 & Recovery phase & $\Delta$ & $P^{+++}$ \\
\hline Weight $(\mathrm{kg})$ & $79.8 \pm 10.4$ & $77.8 \pm 10.9$ & $-1.9 \pm 2.0$ & 0.002 \\
\hline Waist (cm) & $95.7 \pm 10.3$ & $93.7 \pm 9.7$ & $-2.0 \pm 1.4$ & $<0.001$ \\
\hline Glycaemia (mg/dL) & $113.5 \pm 12.0$ & $105.6 \pm 7.4$ & $-7.8 \pm 6.8$ & $<0.001$ \\
\hline $\operatorname{HbA1C}(\%)$ & $6.0 \pm 0.1$ & $5.9 \pm 0.2$ & $-0.1 \pm 0.1$ & $<0.001$ \\
\hline Total cholesterol (mg/dL) & $254.8 \pm 39.8$ & $236.6 \pm 30.0$ & $-18.1 \pm 14.3$ & $<0.001$ \\
\hline HDL cholesterol (mg/dL) & $39.8 \pm 10.5$ & $45.0 \pm 6.1$ & $5.2 \pm 7.4$ & 0.017 \\
\hline LDL cholesterol (mg/dL) & $181(138-226.6)$ & $149(131.4-188.4)$ & $-16.6((-36)-(-4))$ & 0.001 \\
\hline Triglycerides (mg/dL) & $169.4 \pm 29.2$ & $159.4 \pm 28.3$ & $-10.0 \pm 7.10$ & $<0.001$ \\
\hline HOMA-IR & $9.7 \pm 3.2$ & $6.4 \pm 1.8$ & $-3.2 \pm 1.9$ & $<0.001$ \\
\hline $\mathrm{SBP}(\mathrm{mmHg})$ & $130(120-140)$ & $120(110-130)$ & $-10((-20)-(-10))$ & 0.002 \\
\hline $\mathrm{DBP}(\mathrm{mmHg})$ & $89.6 \pm 7.8$ & $83.0 \pm 5.6$ & $-6.6 \pm 6.4$ & $<0.001$ \\
\hline
\end{tabular}

Values are expressed as median (interquartile range) or mean \pm standard deviation.

${ }^{+++}$Statistical comparison between time 0 and recovery phase.

$\Delta$ : variation; HbAlc: glycated hemoglobin; HDL: high-density lipoprotein; LDL: low-density lipoprotein; HOMA-IR: homeostasis model assessment of insulin resistance; SBP: systolic blood pressure; DBP: diastolic blood pressure.

TABLE 3: Pearson correlations of statistically significant hormonal variations between the two phases and number of AR gene CAG triplets with CVRFs variations.

\begin{tabular}{|c|c|c|c|c|}
\hline & $\Delta$-Testosterone & $\Delta$-Estradiol & $\Delta$-IGF-1 & Number of AR gene CAG triplets \\
\hline \multirow{2}{*}{$\Delta$-Weight } & $r:-0.617$ & \multirow{2}{*}{ NS } & \multirow{2}{*}{ NS } & $r: 0.755$ \\
\hline & $P: 0.014$ & & & $P: 0.001$ \\
\hline \multirow{2}{*}{$\Delta$-Waist } & $r:-0.633$ & \multirow{2}{*}{ NS } & \multirow{2}{*}{ NS } & $r: 0.685$ \\
\hline & $P: 0.011$ & & & $P: 0.005$ \\
\hline \multirow{2}{*}{$\Delta$-Glycaemia } & $r:-0.758$ & \multirow{2}{*}{ NS } & \multirow{2}{*}{ NS } & $r: 0.938$ \\
\hline & $P: 0.001$ & & & $P<0.001$ \\
\hline \multirow{2}{*}{$\Delta$-HbAlc } & $r:-0.715$ & \multirow{2}{*}{ NS } & \multirow{2}{*}{ NS } & $r: 0.921$ \\
\hline & $P: 0.003$ & & & $P<0.001$ \\
\hline \multirow{2}{*}{$\Delta$-Total cholesterol } & $r:-0.750$ & \multirow{2}{*}{ NS } & \multirow{2}{*}{ NS } & $r: 0.726$ \\
\hline & $P: 0.001$ & & & $P: 0.002$ \\
\hline \multirow{2}{*}{$\Delta$-HDL cholesterol } & $r: 0.838$ & \multirow{2}{*}{ NS } & \multirow{2}{*}{ NS } & $r:-0.958$ \\
\hline & $P<0.001$ & & & $P<0.001$ \\
\hline \multirow{2}{*}{$\Delta$-LDL cholesterol } & $r:-0.840$ & \multirow{2}{*}{ NS } & \multirow{2}{*}{ NS } & $r: 0.856$ \\
\hline & $P<0.001$ & & & $P<0.001$ \\
\hline \multirow{2}{*}{$\Delta$-Triglycerides } & $r:-0.757$ & \multirow{2}{*}{ NS } & \multirow{2}{*}{ NS } & $r: 0.921$ \\
\hline & $P: 0.001$ & & & $P<0.001$ \\
\hline \multirow{2}{*}{$\Delta$-HOMA-IR } & $r:-0.902$ & \multirow{2}{*}{ NS } & \multirow{2}{*}{ NS } & $r: 0.937$ \\
\hline & $P<0.001$ & & & $P<0.001$ \\
\hline \multirow{2}{*}{$\Delta-\mathrm{SBP}$} & $r:-0.801$ & \multirow{2}{*}{ NS } & \multirow{2}{*}{ NS } & $r: 0.935$ \\
\hline & $P<0.001$ & & & $P<0.001$ \\
\hline \multirow{2}{*}{$\Delta-\mathrm{DBP}$} & $r:-0.828$ & \multirow{2}{*}{ NS } & \multirow{2}{*}{ NS } & $r: 0.965$ \\
\hline & $P<0.001$ & & & $P<0.001$ \\
\hline
\end{tabular}

AR: androgen receptor; CVRFs: cardiovascular risk factors; $\Delta$ : variation; IGF-1: insulin-like growth factor-1; HbAlC: glycated hemoglobin; HDL: high-density lipoprotein; LDL: low-density lipoprotein; HOMA-IR: homeostasis model assessment of insulin resistance; SBP: systolic blood pressure; DBP: diastolic blood pressure; NS: not significant.

administration of replacement cortisol therapy in subjects affected by adrenocortical failure increases and normalizes glycaemia and blood pressure and favours weight recovery [14]. GH replacement therapy, instead, produces an improvement of the lipid profile and increases waist circumference, body mass index (BMI), and glycaemia in patients with $\mathrm{GH}$ deficiency [15]. Similarly, levothyroxine administration in hypothyroid patients induces a decrease in total and LDL cholesterol [16]. Moreover, TRT in hypogonadal males is able to influence metabolic parameters causing a reduction of fasting plasma glucose, HOMA-IR, triglycerides, waist circumference, and usually augmenting HDL cholesterol 
TABLE 4: Influence of AR gene CAG repeat length on metabolic parameters.

\begin{tabular}{lcc}
\hline & \multicolumn{2}{c}{ AR gene CAG repeat length } \\
& $\begin{array}{c}\text { Unstandardized } \beta \text { coefficient } \\
(95 \% \mathrm{CI})^{+++}\end{array}$ & $P$ \\
\hline$\Delta$-Weight $(\mathrm{kg})$ & $0.454(0.023-0.885)$ & 0.041 \\
$\Delta$-Waist $(\mathrm{cm})$ & $0.218((-0.125)-(0.561))$ & $\mathrm{NS}$ \\
$\Delta$-Glycaemia $(\mathrm{mg} / \mathrm{dL})$ & $1.970(1.195-2.745)$ & $<0.001$ \\
$\Delta$-HbAlc $\%)$ & $0.038(0.022-0.053)$ & $<0.001$ \\
$\Delta$-Total cholesterol (mg/dL) & $1.414((-1.562)-(4.390))$ & $\mathrm{NS}$ \\
$\Delta$-HDL cholesterol (mg/dL) & $-1.817((-2.487)-(-1.147))$ & $<0.001$ \\
$\Delta$-LDL cholesterol (mg/dL) & $2.845((-0.005)-(5.696))$ & 0.050 \\
$\Delta$-Triglycerides (mg/dL) & $1.927(1.023-2.832)$ & $<0.001$ \\
$\Delta$-HOMA-IR & $0.349(0.177-0.520)$ & $<0.001$ \\
$\Delta$-SBP (mmHg) & $2.453(1.333-3.574)$ & $<0.001$ \\
$\Delta$-DBP (mmHg) & $1.671(1.134-2.209)$ & $<0.001$ \\
\hline
\end{tabular}

+++ adjusted for $\Delta$-testosterone; AR: androgen receptor; CI: confidence interval; $\Delta$ : variation; HbAlc: glycated hemoglobin; HDL: high-density lipoprotein; LDL: low-density lipoprotein; HOMA-IR: homeostasis model assessment of insulin resistance; SBP: systolic blood pressure; DBP: diastolic blood pressure; NS: not significant.

$[19,31-34]$; also, estrogens, which increase after TRT due to aromatase-mediated conversion $[35,36]$, have been found to be positively associated with metabolic syndrome [37].

In our subjects we found that shorter length of $\mathrm{AR}$ gene CAG repeat polymorphism favours the improvement of many of the CVRFs after TRT independently from the metabolic effects of the pituitary-function replacement therapies. Our findings agree with a large study carried out on 1859 men aged 20-79 years showing that subject with CAG repeat length lower than 22 had lower levels of BMI, glycaemia, SBP, and percentage of hypertension [13]. Moreover, our data confirm the tendency, already highlighted in the only other study on the same topic, which included 66 men affected by hypogonadism of various aetiologies (i.e., primary, secondary, and late onset hypogonadism), reporting that the SBP and DBP decrease following TRT occurred mainly in subjects with shorter CAG repeat length [38]. It is also worth mentioning that, in their study, no influence of AR gene CAG repeat polymorphism on lipid profile improvement was evident [38]; probably the heterogeneity of the sample examined by those authors and the different statistical methods used could explain this discrepancy.

Nevertheless, we cannot avoid mentioning those studies which found a completely different association between AR gene CAG polymorphism and metabolic profile. In fact, Skjærpe et al. studying 172 men, aged 60-80 years, found that those with a CAG length below 21 had higher values of glycaemia, c-peptide, and HbAlc, as compared to those with CAG length over 21 [39]. In line with these findings, in 131 men undergoing coronary angiography, it has been reported that those with short AR had significant coronary artery disease more frequently than men with long AR [12]. Moreover, in 110 healthy men the number of AR gene CAG repeats was found to be positively correlated with
HDL cholesterol levels and flow-mediated vasodilatation, a measure of endothelial function [40].

Interestingly, in our sample TRT led to an increase in HDL cholesterol. This finding is in agreement with a recent meta-analysis [41] and with the previously mentioned work by Zitzmann and Nieschlag [38] who reported a significant increase in HDL cholesterol from $42.4 \pm 11.3 \mathrm{mg} / \mathrm{dL}$ to 50.1 $\pm 8.9 \mathrm{mg} / \mathrm{dL}$ (resp., mean and standard deviation). However, at variance with this, some evidence shows that TRT may also have the opposite effect on HDL cholesterol levels in hypogonadal men $[42,43]$. Although a variety of factors, like duration of study, fat distribution, obesity, diet, age, alcohol intake, exercise, and smoking [38, 43], have been considered to explain these diverse results, in our opinion more attention should be given specifically to the length of CAG polymorphism which could represent the dominating factor able to condition the variations of HDL cholesterol following TRT.

\section{Conclusions}

In conclusion, our study suggests that, in men affected by postsurgical hypogonadotropic hypogonadism, the shorter length of AR gene CAG tract is associated with an improved metabolic effect of TRT, independently of the effects of other concomitant pituitary-function replacement therapies. If our data will be confirmed by further studies, genetic analysis of AR gene CAG repeat polymorphism could be introduced in clinical practice as an adjunctive factor in evaluating cardiovascular risk in hypogonadal men undergoing TRT.

\section{Conflict of Interests}

All authors report no conflict of interests related to this study. No external funding, apart from the support of the authors' institution, was available for this study.

\section{References}

[1] D. B. Lubahn, D. R. Joseph, P. M. Sullivan, H. F. Willard, F. S. French, and E. M. Wilson, "Cloning of human androgen receptor complementary DNA and localization to the X chromomose," Science, vol. 240, no. 4850, pp. 327-330, 1988.

[2] A. Ferlin, L. Bartoloni, G. Rizzo, A. Roverato, A. Garolla, and C. Foresta, "Androgen receptor gene CAG and GGC repeat lengths in idiopathic male infertility," Molecular Human Reproduction, vol. 10, no. 6, pp. 417-421, 2004.

[3] N. L. Chamberlain, E. D. Driver, and R. L. Miesfeld, “The length and location of CAG trinucleotide repeats in the androgen receptor N-terminal domain affect transactivation function," Nucleic Acids Research, vol. 22, no. 15, pp. 3181-3186, 1994.

[4] M. Katsuno, H. Adachi, F. Tanaka, and G. Sobue, "Spinal and bulbar muscular atrophy: ligand-dependent pathogenesis and therapeutic perspectives," Journal of Molecular Medicine, vol. 82, no. 5, pp. 298-307, 2004.

[5] A. W. Hsing, Y.-T. Gao, G. Wu et al., "Polymorphic CAG and GGN repeat lengths in the androgen receptor gene and prostate cancer risk: a population-based case-control study in China," Cancer Research, vol. 60, no. 18, pp. 5111-5116, 2000. 
[6] E. Giovannucci, M. J. Stampfer, A. Chan et al., "CAG repeat within the androgen receptor gene and incidence of surgery for benign prostatic hyperplasia in U.S. physicians," Prostate, vol. 39, no. 2, pp. 130-134, 1999.

[7] M. Zitzmann, M. Depenbusch, J. Gromoll, and E. Nieschlag, "Prostate volume and growth in testosterone-substituted hypogonadal men are dependent on the CAG repeat polymorphism of the androgen receptor gene: a longitudinal pharmacogenetic study," Journal of Clinical Endocrinology \& Metabolism, vol. 88, no. 5, pp. 2049-2054, 2003.

[8] S. Von Eckardstein, A. Syska, J. Gromoll, A. Kamischke, M. Simoni, and E. Nieschlag, "Inverse correlation between sperm concentration and number of androgen receptor CAG repeats in normal men," Journal of Clinical Endocrinology \& Metabolism, vol. 86, no. 6, pp. 2585-2590, 2001.

[9] A. Mifsud, C. K. S. Sim, H. Boettger-Tong et al., "Trinucleotide (CAG) repeat polymorphisms in the androgen receptor gene: molecular markers of risk for male infertility," Fertility and Sterility, vol. 75, no. 2, pp. 275-281, 2001.

[10] M. Zitzmann, M. Brune, B. Kornmann, J. Gromoll, R. Junker, and E. Nieschlag, "The CAG repeat polymorphism in the androgen receptor gene affects bone density and bone metabolism in healthy males," Clinical Endocrinology, vol. 55, no. 5, pp. 649657, 2001.

[11] M. Hersberger, J. Muntwyler, H. Funke et al., "The CAG repeat polymorphism in the androgen receptor gene is associated with HDL-cholesterol but not with coronary atherosclerosis or myocardial infarction," Clinical Chemistry, vol. 51, no. 7, pp. 1110-1115, 2005.

[12] M. Alevizaki, A. T. Cimponeriu, M. Garofallaki et al., "The androgen receptor gene CAG polymorphism is associated with the severity of coronary artery disease in men," Clinical Endocrinology, vol. 59, no. 6, pp. 749-755, 2003.

[13] R. Haring, F. Ernst, C. Schurmann et al., "The androgen receptor CAG repeat polymorphism as a risk factor of low serum testosterone and its cardiometabolic effects in men," International Journal of Andrology, vol. 35, no. 4, pp. 511-520, 2012.

[14] A. Granata, G. Tirabassi, V. Pugni et al., "Sexual dysfunctions in men affected by autoimmune addison's disease before and after short-term gluco-and mineralocorticoid replacement therapy," Journal of Sexual Medicine, vol. 10, no. 8, pp. 20362043, 2013.

[15] K. M. Claessen, N. M. Appelman-Dijkstra, D. M. Adoptie et al., "Metabolic profile in growth hormone-deficient (GHD) adults after long-term recombinant human growth hormone (rhGH) therapy," Journal of Clinical Endocrinology \& Metabolism, vol. 98, no. 1, pp. 352-361, 2013.

[16] F. Monzani, N. Caraccio, M. Kozàkowà et al., "Effect of levothyroxine replacement on lipid profile and intima-media thickness in subclinical hypothyroidism: a double-blind, placebo-controlled study," Journal of Clinical Endocrinology \& Metabolism, vol. 89, no. 5, pp. 2099-2106, 2004.

[17] G. Tirabassi, E. Faloia, R. Papa, G. Furlani, M. Boscaro, and G. Arnaldi, "Use of the desmopressin test in the differential diagnosis of pseudo-Cushing state from Cushing's disease," Journal of Clinical Endocrinology \& Metabolism, vol. 95, no. 3, pp. 1115-1122, 2010.

[18] G. Arnaldi, G. Tirabassi, R. Papa et al., "Human corticotropin releasing hormone test performance in the differential diagnosis between Cushing's disease and pseudo-Cushing state is enhanced by combined ACTH and cortisol analysis," European Journal of Endocrinology, vol. 160, no. 6, pp. 891-898, 2009.

[19] G. Tirabassi, A. Gioia, L. Giovannini et al., "Testosterone and cardiovascular risk," Internal and Emergency Medicine, vol. 8, no. 1, supplement 1, pp. 65-69, 2013.

[20] S. Bhasin, G. R. Cunningham, F. J. Hayes et al., "Testosterone therapy in men with androgen deficiency syndromes: an endocrine society clinical practice guideline," Journal of Clinical Endocrinology \& Metabolism, vol. 95, no. 6, pp. 2536-2559, 2010.

[21] F. Saad, A. Kamischke, A. Yassin et al., "More than eight years' hands-on experience with the novel long-acting parenteral testosterone undecanoate," Asian Journal of Andrology, vol. 9, no. 3, pp. 291-297, 2007.

[22] E. Gabellieri, L. Chiovato, M. Lage, A. I. Castro, and F. F. Casanueva, "Testing growth hormone deficiency in adults," Frontiers of Hormone Research, vol. 38, pp. 139-144, 2010.

[23] L. Persani, "Clinical review: central hypothyroidism: pathogenic, diagnostic, and therapeutic challenges," Journal of Clinical Endocrinology \& Metabolism, vol. 97, no. 9, pp. 3068-3078, 2012.

[24] A. B. Grossman, "The diagnosis and management of central hypoadrenalism," Journal of Clinical Endocrinology \& Metabolism, vol. 95, no. 11, pp. 4855-4863, 2010.

[25] E. Faloia, G. Tirabassi, P. Canibus, and M. Boscaro, "Protective effect of leg fat against cardiovascular risk factors in obese premenopausal women," Nutrition, Metabolism and Cardiovascular Diseases, vol. 19, no. 1, pp. 39-44, 2009.

[26] L. Costarelli, E. Muti, M. Malavolta et al., "Distinctive modulation of inflammatory and metabolic parameters in relation to zinc nutritional status in adult overweight/obese subjects," Journal of Nutritional Biochemistry, vol. 21, no. 5, pp. 432-437, 2010.

[27] W. T. Friedewald, R. I. Levy, and D. S. Fredrickson, "Estimation of the concentration of low-density lipoprotein cholesterol in plasma, without use of the preparative ultracentrifuge," Clinical Chemistry, vol. 18, no. 6, pp. 499-502, 1972.

[28] N. Delli Muti, A. Agarwal, E. Buldreghini et al., "Have androgen receptor gene CAG and GGC repeat polymorphisms an effect on sperm motility in infertile men?" Andrologia, 2013.

[29] G. Tirabassi, R. Papa, E. Faloia, M. Boscaro, and G. Arnaldi, "Corticotrophin-releasing hormone and desmopressin tests in the differential diagnosis between Cushing's disease and pseudo-Cushing state: a comparative study," Clinical Endocrinology, vol. 75, no. 5, pp. 666-672, 2011.

[30] G. Arnaldi, T. Mancini, G. Tirabassi, L. Trementino, and M. Boscaro, "Advances in the epidemiology, pathogenesis, and management of Cushing's syndrome complications," Journal of Endocrinological Investigation, vol. 35, no. 4, pp. 434-448, 2012.

[31] G. Corona, G. Rastrelli, A. Morelli, L. Vignozzi, E. Mannucci, and M. Maggi, "Hypogonadism and metabolic syndrome," Journal of Endocrinological Investigation, vol. 34, no. 7, pp. 557567, 2011.

[32] G. Corona, G. Rastrelli, L. Vignozzi, E. Mannucci, and M. Maggi, "Testosterone, cardiovascular disease and the metabolic syndrome," Best Practice \& Research, vol. 25, no. 2, pp. 337-353, 2011.

[33] G. Corona, G. Rastrelli, and M. Maggi, "Diagnosis and treatment of late-onset hypogonadism: systematic review and metaanalysis of TRT outcomes," Best Practice \& Research Clinical Endocrinology \& Metabolism, vol. 27, no. 4, pp. 557-579, 2013. 
[34] F. Saad, A. Aversa, A. M. Isidori, and L. J. Gooren, "Testosterone as potential effective therapy in treatment of obesity in men with testosterone deficiency: a review," Current Diabetes Reviews, vol. 8, no. 2, pp. 131-143, 2012.

[35] E. Nieschlag, D. Büchter, S. Von Eckardstein, K. Abshagen, M. Simoni, and H. M. Behre, "Repeated intramuscular injections of testosterone undecanoate for substitution therapy in hypogonadal men," Clinical Endocrinology, vol. 51, no. 6, pp. 757-763, 1999.

[36] C. Wang, M. Harnett, A. S. Dobs, and R. S. Swerdloff, "Pharmacokinetics and safety of long-acting testosterone undecanoate injections in hypogonadal men: an 84-week phase III clinical trial," Journal of Andrology, vol. 31, no. 5, pp. 457-465, 2010.

[37] M. Maggio, F. Lauretani, G. P. Ceda et al., "Estradiol and metabolic syndrome in older Italian men: the InCHIANTI study," Journal of Andrology, vol. 31, no. 2, pp. 155-162, 2010.

[38] M. Zitzmann and E. Nieschlag, "Androgen receptor gene CAG repeat length and body mass index modulate the safety of long-term intramuscular testosterone undecanoate therapy in hypogonadal men," Journal of Clinical Endocrinology \& Metabolism, vol. 92, no. 10, pp. 3844-3853, 2007.

[39] P. A. Skjærpe, Y. L. Giwercman, A. Giwercman, and J. Svartberg, "Androgen receptor gene polymorphism and the metabolic syndrome in 60-80 years old Norwegian men," International Journal of Andrology, vol. 33, no. 3, pp. 500-506, 2010.

[40] M. Zitzmann, M. Brune, B. Kornmann et al., "The CAG repeat polymorphism in the $\mathrm{AR}$ gene affects high density lipoprotein cholesterol and arterial vasoreactivity," Journal of Clinical Endocrinology \& Metabolism, vol. 86, no. 10, pp. 48674873, 2001.

[41] G. Corona, M. Monami, G. Rastrelli et al., "Testosterone and metabolic syndrome: a meta-analysis study," Journal of Sexual Medicine, vol. 8, no. 1, pp. 272-283, 2011.

[42] A. S. Dobs, P. S. Bachorik, S. Arver et al., "Interrelationships among lipoprotein levels, sex hormones, anthropometric parameters, and age in hypogonadal men treated for 1 year with a permeation-enhanced testosterone transdermal system," Journal of Clinical Endocrinology \& Metabolism, vol. 86, no. 3, pp. 1026-1033, 2001.

[43] R. Sorva, T. Kuusi, M.-R. Taskinen, J. Perheentupa, and E. A. Nikkila, "Testosterone substitution increases the activity of lipoprotein lipase and hepatic lipase in hypogonadal males," Atherosclerosis, vol. 69, no. 2-3, pp. 191-197, 1988. 


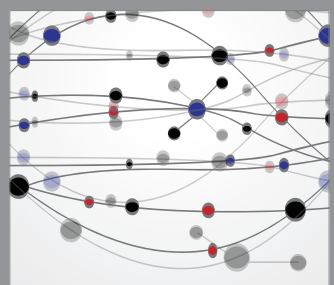

The Scientific World Journal
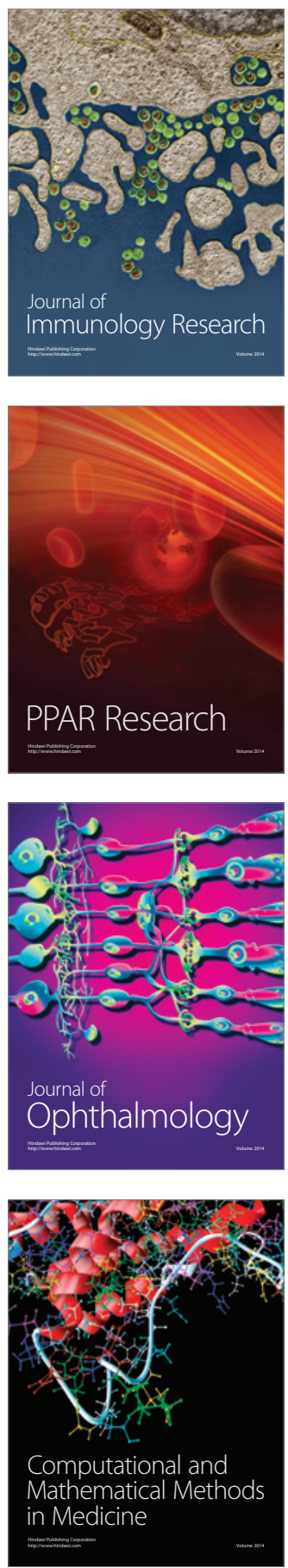

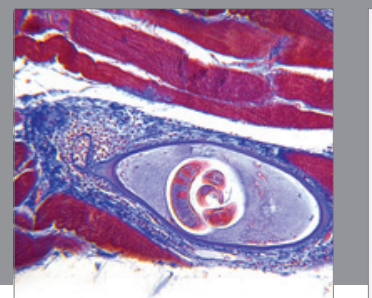

Gastroenterology

Research and Practice
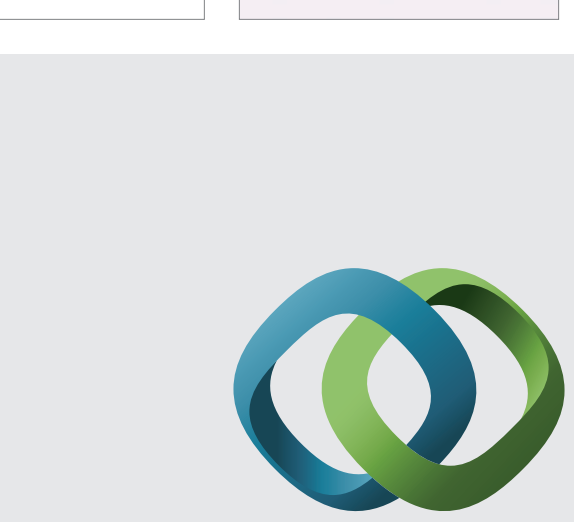

\section{Hindawi}

Submit your manuscripts at

http://www.hindawi.com
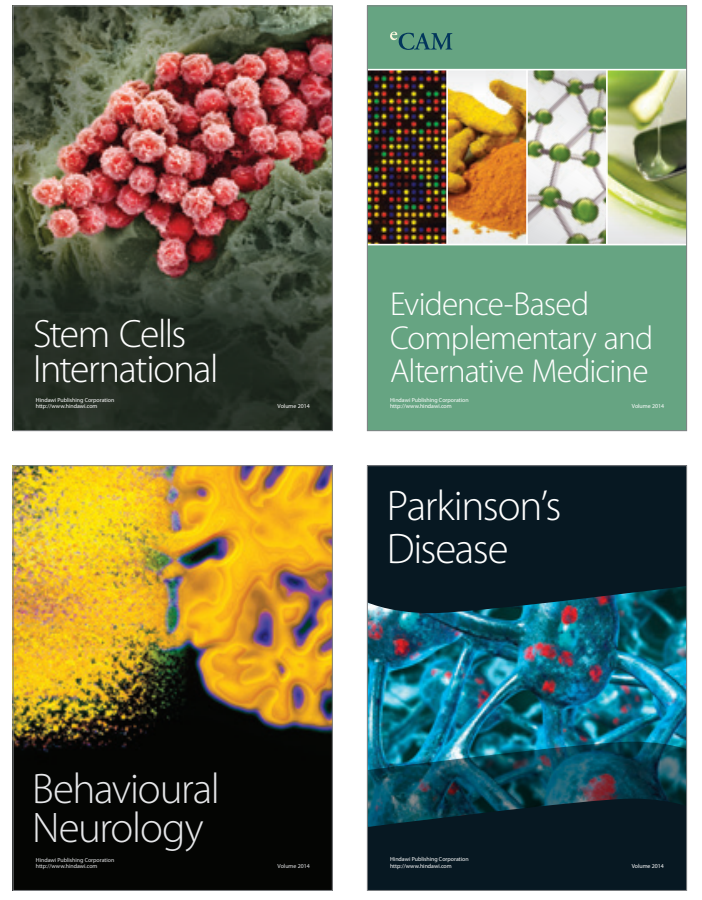
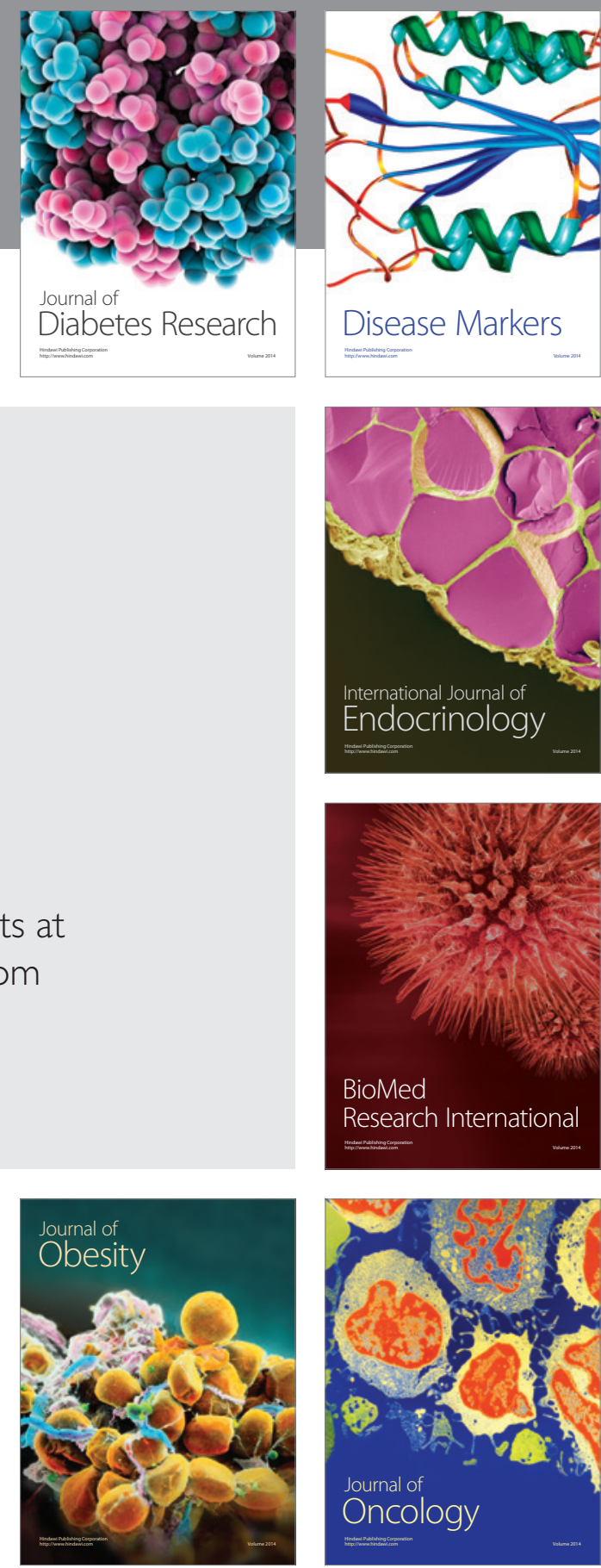

Disease Markers
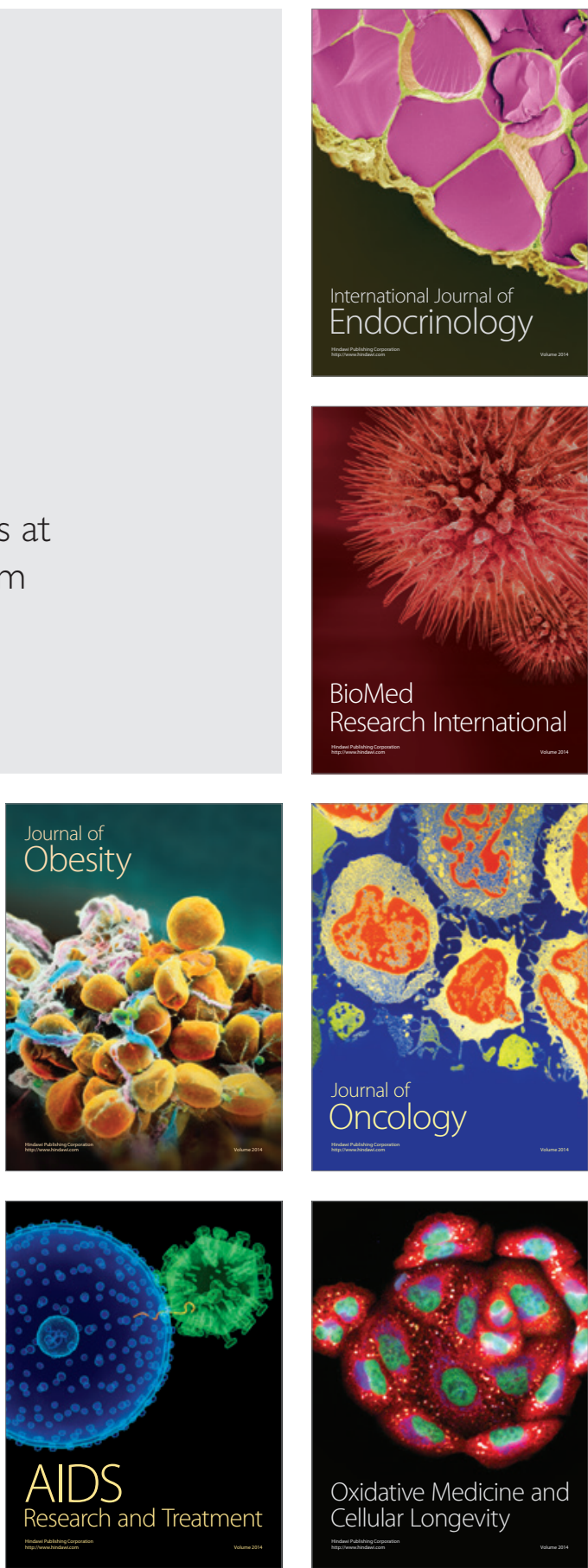